\title{
The Danish Crime Harm Index: How It Works and Why It Matters
}

\author{
Helle Aagaard Andersen ${ }^{1}$ • Katrin Mueller-Johnson ${ }^{2}$
}

Published online: 7 May 2018

(C) The Author(s) 2018

\begin{abstract}
Research Question How can Danish Police calculate a single metric, similar to the Cambridge Crime Harm Index (Sherman, Neyroud and Neyroud 2016), that allows the total harm from all victim-reported crimes to be compared over time and across different areas, offenders, gangs, and victims, and what difference can it make in analyzing crime?

Data This analysis examines 2,129,550 reported criminal incidents in the national police crime reports spanning 16 years (2011-2016) and 93\% of all of the crime categories in the Danish Criminal Code, excluding those that are primarily detected through proactive policing. It uses the officially recommended days of imprisonment for each crime type to generate the weight of punishment that would be applied if one offender were convicted of each crime, by standards independent of prior criminal history of the offender.

Methods The analysis coded the recommended number of days in prison for each offense type based on guidelines set out by the Danish Office of Public Prosecutions. The sentencing value from the prosecutor guidelines was reviewed by five prosecutors. The reliability between the prosecutor ratings and the prosecutor guidelines' sentencing value was calculated by using Cronbach's alpha $(\alpha=0.93)$.

Findings While the count of all victim-reported criminal events in Denmark in 2016 had dropped by $14 \%$ (54,000 fewer crimes) from 393,000 in 2011, the Danish Crime Harm Index value (after excluding adult rapes due to a 2015 change in reporting rules) for all victim-reported crimes rose by $0.5 \%$ or 46,640 days of recommended imprisonment, from 9,714,057 recommended days of imprisonment in 2011 to 9,760,697 days in 2016. Including rapes, the Danish CHI rose by 6\% from 2011 through 2016.
\end{abstract}

Katrin Mueller-Johnson

kum20@cam.ac.uk

1 Danish National Police, National Centre of Investigation (NCI), Glostrup, Denmark

2 University of Cambridge, Cambridge, UK 
Conclusions Because the Danish Crime Harm Index (DCHI) can lend a completely different perspective (and opposite direction) for interpreting crime trends, it can do the same across individuals and areas within Denmark. The value of adding the DCHI totals to the historic reporting of crime counts would seem to be substantial, at all levels of analysis.

Keywords Crime Harm Index · Crime trends · Crime severity

\section{Introduction}

How should police target priorities for preventing and solving crimes? What is the best way to identify patterns of crime concentrations in a community, a society, individual offenders, or victims - by sheer volume of crimes or by the overall harm of crimes? Should all crimes be counted as equal or should some types of crime be given more weight than others, as in the formula for the Cambridge Crime Harm Index (CCHI) (Sherman 2007, 2011, Sherman 2013; Sherman, Neyroud and Neyroud 2016)? With evidence-based policing on the rise, and the recent development of crime harm metrics in the UK (Sherman et al. 2016), Sweden (Rinaldo 2016), the USA (Ratcliffe 2014; Mitchell 2017), Canada (Babyak et al. 2009), New Zealand (Curtis-Ham and Walton 2017), and Australia (House 2018), it is timely to consider how best to measure crime. That question must be answered before we can answer the larger question: How can we make optimal use of scarce resources in policing?

Examining ways to understand whether policing methods succeed in keeping people safe, Sherman et al. (2016) argued that simply reducing the raw number of crimes is not always the best public safety metric. They argue that the combining all of crimes of all types into a simple count is misleading, as not all crimes are created equal. However, in the Danish Police, crime count totals are still compared from one period to another as the dominant method of establishing whether crime has gone up or down. Moreover, crime count and crime frequency are used to direct patrols (hotspot policing) and to identify vulnerable areas. Each year the Danish Police publish a crime count report to help decide how to distribute resources among the nation's 12 police districts. Leaders of those Danish Police districts also use these crime counts to decide which crime areas within districts will receive extra resources. While this annual report also contains a qualitative element that tries to address the harm associated with each type of crime, analysts have challenged the value of that commentary. They suggest that the annual report is too descriptive when it comes to crime harm and too focused on numbers when it comes to crime count.

To address this critique and to develop a more effective way to target places, offenders, and victims, the Danish Police in recent years developed a new way to measure the harm related to each criminal offense. This method is called POLSPOT (Rigspolitiet 2010). POLSPOT relies on the idea that some offenses are more serious than others, so that each criminal code is assigned a weight; for a detailed description, see Andersen (2018). Yet these weightings are based on a few police officers' subjective assessment on the harm related to the offenses on a scale from 1 to 100 , without reference to any systematic opinion surveys of police or the public. It draws no guidance from prosecution or sentencing practices. Even among the few officers making the 
assessments, POLSPOT employs no test of inter-rater reliability. These shortcomings have limited the use of POLSPOT in police districts, where neither police leaders nor crime analysts regard the system as a fully valid basis for targeting police resources.

Nonetheless, the basic idea behind POLSPOT is the same as for the Cambridge CHI: the fact that the total, un-weighted number of crimes does not capture the impact that criminal offenses have on society. POLSPOT can therefore serve as a stepping stone to a more evidence-based way of measuring crime harm and supporting the broader and complex decision processes for targeting police resources Denmark.

Accepting the argument by Sherman et al. (2016) that not all crimes are created equal and that "counting them as if they are fosters distortion of risk assessments, resource allocation, and accountability" (Sherman et al. 2016, p. 1), this study introduces Danish Police to the concept of measuring crime harm in addition to, but not instead of, crime counts. In 2007, Sherman published a generic proposal for a weighted Crime Harm Index (CHI), which he later fine-tuned with colleagues for England and Wales by applying the sentencing guidelines for that jurisdiction (Sherman, Neyroud \& Neyroud 2016). The sentencing guidelines they reference, now posted on the Cambridge Institute of Criminology website (see http://www.crim.cam.ac.uk/ and click on "Cambridge Crime Harm Index" in upper right-hand corner.), contain a "starting point" for sentencing each type of crime. This number of days is intended to be a "pure" value of the crime impact on victims and society and does not take into account other sentencing criteria, including offenders' prior records, nor aggravating or mitigating circumstances of each specific crime. That "purity" is the major reason not to use the average sentence actually given, which can be heavily distorted by the prior record of persons committing each crime. Yet from a victim perspective, as Sherman points out, it matters little whether one is murdered by a first offender or a career criminal: the harm to the victim is equal. Hence, an offense-focused approach seems more useful for resource allocation than average actual sentences.

An additional problem the Cambridge $\mathrm{CHI}$ addresses is that proactive policing of such offenses as possessing illegal drugs or shop-theft can drive "crime" up or down based on policing resource decisions. The more arrests, the more "crime" this counting system counts. Sherman et al. (2016) conclude that proactively generated crime detection by police and organizational victims should be excluded from any $\mathrm{CHI}$ in any country, since proactively generated crime detections do not reflect changes in harm experienced by the public.

Replicating the Cambridge CHI in Denmark, however, is difficult because no such sentencing guidelines have been established for judges in Denmark. It is therefore the aim of this research to create a Danish CHI that can serve as a meaningful "bottom line" indicator of whether public safety is actually improving or declining in any given year or place.

\section{Research Questions}

The specific research questions for this study are as follows:

a) What is the best way to create a Danish Crime Harm Index based on the principles of the Cambridge CHI? 
b) How does a Danish CHI, when applied to Danish national police data for 2016, change the relative distribution of proportionate impact of different crime types compared to the raw number of each offense type?

c) If the Danish CHI is applied to annual national police crime data from to 2011 to 2016, is the decrease in crime count frequency paralleled by a decrease in Danish CHI value?

The creation of a Danish CHI has several practical and policy implications: Besides the purpose of identifying harm-spots (supplementing crime count "hot spots") and finding the "power few" in relation to resource allocation, a Danish CHI can be used as a more informative metric when comparing changes over time in crime. Moreover, a Danish CHI can be used when setting up randomized control trials and comparing groups (treatment vs. control) to investigate if baseline equality between the groups has been met and also for evidence-based targeting of offenders and victims. Therefore, a Danish CHI has the potential to serve as a stepping stone to bring Danish Police one step closer to performing more evidence-based policing.

\section{Data}

The data used to create a Danish CHI was a 6-year universe of the counts of all eligible crime types. The crime counts contain all reported crimes classified by the Danish Criminal Code from 2011 to 2016, plus selected types of offenses from "special law." All reported offenses were registered, categorized and stored in POLSAS by the use of crime codes, and identified by a five-digit number. Offenses recorded prior to 2011 were categorized differently and were therefore excluded from the study.

\section{Crime Counts and Crime Grouping}

Crime data used in this research was extracted from Danish Police's crime management system (POLSAS) via the data extraction tool POLMAP into Microsoft Excel. All reported crimes from 1 January 2011 to 31 December 2016 were extracted and converted into an Excel file. The data extracted on the 1 June $2017,{ }^{1}$ with all criminal categories in relation to the Criminal Code included. All criminal codes in relation to "special law" (such as all traffic offenses) were excluded, except reported crimes in relation to illegal firearms, illegal possession of knives and other weapons. After the data extraction, police-initiated offenses such as narcotics and handling of stolen goods were excluded.

In total, 504 criminal code numbers are included in the crime count. The total number of offenses each year is depicted in Fig. 1.

On the basis of these 504 criminal code numbers, 46 crime categories were constructed. The crime categories were constructed on the basis of the legal paragraph in the Criminal Code. All categories were reviewed by two prosecutors in order to ensure that all groupings were created according to the Criminal Code and that no

\footnotetext{
${ }^{1}$ The data extraction was carried out by the data unit, NCI, Danish National Police, in order to ensure that the data set used in this thesis corresponded with the data set used in the official crime count.
} 


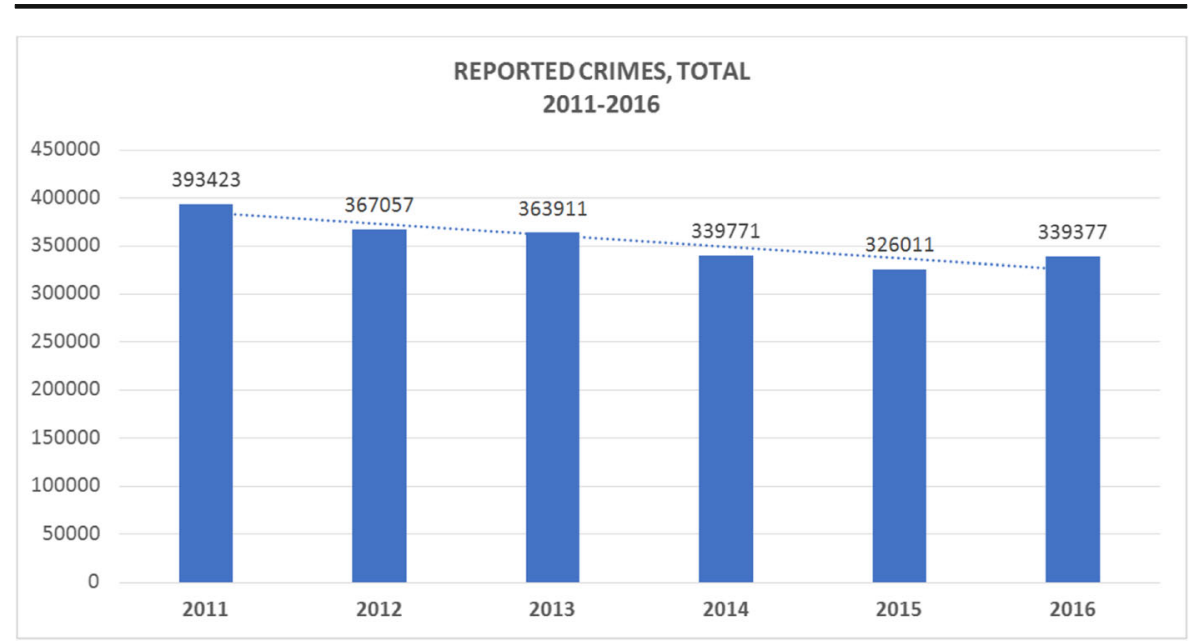

Fig. 1 Annual total of reported crimes, Criminal Code

categories overlapped each other. An overview of all categories can be found in Andersen (2018: Appendix A).

\section{Excluded Offenses}

Fully 93\% of all reported crimes from 2011 to 2016 are included in the grouped categories. The percentage of reported crimes that are not included varies very little from 2011 to 2016. This variation ranged little by year, from as high as $6.85 \%$ of offenses excluded to as low as $6.05 \%$ excluded (Andersen 2018: Table 1). A list of all crimes excluded can be found in Andersen (2018). Some offenses were excluded because they are very rare and are not considered serious crimes, such as "illegal begging" (11 reported offenses in 2016) or "unauthorized access to electronic material" (77 reported crimes in 2016). Others were excluded because the offense is policegenerated (e.g., possession of stolen goods, narcotics possession, smuggling), following the principles of Sherman et al. (2016).

Moreover, some offenses were excluded after being grouped. This was the case for the categories blackmailing, counterfeiting, and embezzlement, for technical reasons detailed in Andersen (2018). Further, all terror-related offenses are excluded from the index, since they are low in frequency but can be high in harm. Since all terror-related offenses are handled by the Danish Security and Intelligence Service (DSIS), it is more useful for the purpose of using $\mathrm{CHI}$ to leave terror offenses out of the final index.

\section{Data Limitations of Code-Grouping}

The crime code number that is given to all reported crimes refers to the section of the Criminal Code the offense relates to, but the criminal code number is not identical to the legal paragraph in the criminal code. In addition, several criminal code numbers can be linked with the same legal paragraph. These complexities pose a great challenge in relation to the groupings of criminal code numbers. To make sure that the grouping 
of criminal code numbers corresponds with the legal paragraphs in the Danish Criminal Code, a prosecutor was assigned to assist with the grouping. A second prosecutor reviewed the groupings, and a few changes were made to the original grouping. However, some groups had to be combined even though they might differ slightly when it comes to sentencing. This issue is addressed in detail in Andersen (2018).

\section{A 2015 Change in Rape Recording Practices}

In the last 2 years of the data analyzed (2015-2016), a new procedure was used that increased the proportion of rape reports that was counted as reported crimes. In 2015, the Danish Police service was criticized for not recording reported rapes, but instead assigning the report with an investigation code. However, when a case is assigned with an investigation code number, the case will not be a part of the data set extracted via POLMAP. As a consequence of this critique, the Danish Police instructed all officers to use the criminal code number in rape cases from 2015 onward. When rapes were no longer assigned an investigation code number, but instead were assigned a criminal case number, the number of recorded rapes. However, this increase in reported rapes does not necessarily reflect an increase in rapes committed. When comparing numbers - and harm-scores - over time, this is a very important limitation to data. Thus, the analysis below reports the Danish CHI trends nationally over time both including and excluding the data on rapes of adult victims.

\section{Methods: Creating the Danish Index Weightings}

The methods used for this analysis followed the five principles described by Sherman et al. (2016). First, any crime harm metric should be democratic, reflecting a procedure for the resolution of conflicting viewpoints adopted by a democratic government accountable to the will of the people. Second, a crime harm metric must be reliable and be consistently applied to all units of analysis. Third, a crime harm metric must not be complex and has to be inexpensive to develop and use. Fourth, the metric has to be valid and measure the harm simply and as objectively as possible. Validity also means being as specific as possible in relation to particular crimes. Lastly, the crime harm metric must be easily operationalized.

In the absence of sentencing guidelines with "pure" starting points, this study planned to consult prosecutors from the 12 Danish police districts was considered. The reason for consulting prosecutors instead of judges (as in Sweden, see Rinaldo 2016) is that in a Danish context, judges are rarely specialized in criminal law. Because judges preside in both civil and criminal cases, years can pass between a judge being assigned a first and second serious crime, such as a rape case. Yet prosecutors are more specialized, working only in court in relation to criminal cases.

Consultations with prosecutors in a pilot test, however, revealed that they all consulted the guidelines from The Danish Director of Public Prosecutions (DPP) specifying what sentence the prosecutor should ask for in court when having a firsttime offender charged without mitigation or aggravating factors (Anklagemyndigheden 2017). The prosecutor guidelines are available to the public as well as to the prosecutors and are available on almost all crime areas. The pilot testing revealed that, instead of rating the listed crimes based on estimates or experience, the prosecutors instead turned 
to the prosecutor guidelines. The prosecutor guidelines were therefore adopted to provide the crime harm metrics for the analysis, as measured by the number of days of recommended imprisonment.

\section{Prosecutor Guidelines}

The prosecutor guidelines specify what sentence a prosecutor should ask for in court when a first-time offender is charged with a crime. The DPP guidelines are only to be applied when no mitigating or aggravating factors are present and the offender is over 18 years old (Anklagemyndigheden 2017). These guidelines are not stored in one document, but are to be found in different documents in relation to different sections of the Criminal Code. However, in recent years many of the guidelines are combined in fewer documents, which increases their availability. The prosecutor guidelines are continuously assessed and updated (Anklagemyndigheden 2017).

\section{Testing and Validation Procedure}

Based on the prosecutor guidelines, a self-completion questionnaire was created (see Andersen 2018, Appendix C). For each offense, the prosecutor guideline value was assigned and each prosecutor was asked to evaluate if this value was equal to what a first-time offender would receive for the offense with no mitigating or aggravating factors. The questionnaire was set up by using Excel and information about how to fill out the questionnaire was presented in an attached Word document (Andersen 2018: Appendix D). The prosecutors could either "agree" with the value based on the prosecutor guidelines or "disagree." If the prosecutors disagreed, they were asked to type in their own rating. Applying such an approach opens up for a risk of priming (Bryman 2004). Priming is a theory within psychology that takes into consideration how implicit memory affects responses; in this case, presenting the DPP value before asking the respondent about how he/she would rate the offense. It could be argued that due to the attention to the DPP value, the respondent will be more likely to agree with this value than if the respondent would have had to fill out the questionnaire without any set value. However, the pilot testing indicated that a such approach was not suitable, as the prosecutors would look up the DPP value anyway before answering the questions. It was therefore decided that despite the risk of priming, this was the best method available.

The prosecutors were asked to rate 43 crime categories. In order to minimize the prosecutors' own interpretation of the crime categories, small written examples of each offense type were given, e.g., "rape, victim over 18 years old" or "possession of child pornography, limited level 2 and level 3 material." These written examples served as a guidance to the prosecutors in order to rate an average offense with no mitigating or aggravating factors. All examples were written on the basis of a manual examination of cases in all crime categories and reviewed by prosecutors who were not part of the ratings.

Based on pilot testing performed by a former prosecutor, it was estimated that it would take around $1 \mathrm{~h}$ to fill out the questionnaire. The questionnaire was electronic and sent out to the participants via email. 


\section{Raters}

The original plan to get one prosecutor from each of the 12 districts to fill out the questionnaire was not possible. Instead, only five prosecutors ended up filling out the questionnaire. All five prosecutors have more than 5 years of experience with the Danish Police. None of the five prosecutors comes from the same district and none of the prosecutors works in the same court.

\section{Procedure}

All the participating prosecutors were contacted by email. Those who agreed to participate were telephoned by the first author for an in-depth explanation about the study and their role in the ratings. Further, it was possible to meet with four out of five prosecutors in order to discuss the study in person. The prosecutors were not given anything in return. The questionnaires were completed by the prosecutors themselves and then emailed back to the first author. On two occasions, the prosecutors were contacted afterward as some categories were not rated. The prosecutors were asked to fill out the remaining categories and once again thanked for their time invested in this project.

The prosecutors reported back that the estimate of time was accurate and that they spent a little under $1.5 \mathrm{~h}$ filling it out (all prosecutor ratings are displayed in Andersen 2018, Appendix F).

\section{Testing for Inter-rater Reliability}

In order to test how the ratings from the prosecutors differed from the prosecutor guidelines, a Cronbach's alpha test was performed. The Cronbach's alpha test is a reliability test for measuring the level of internal consistency (Cronbach 1951). The Cronbach's alpha will generally increase when the correlations between the items increase. The maximum value for the Cronbach's alpha is 1 and usually the minimum value is 0 (however, negative values can occur). Two tests were performed in STATA in order to test (a) the correlation between the ratings of the five prosecutors and (b) the correlation between the average of all five prosecutor ratings and the prosecutor guidelines. The correlation between the ratings of the five prosecutors was calculated to $\alpha=0.78$. This value indicates a good internal consistency between the prosecutor ratings; however, differences occur. The second test was calculated to test the correlation between the average of the five prosecutor ratings and the value based on the prosecutor guidelines. The Cronbach's alpha value was calculated to $\alpha=0.93$ which indicated a very high level of agreement.

\section{Converting Fines to Crime Harm Weightings}

In some cases, e.g., minor theft, the offense is punished with a fine. In order to convert this fine to actual days in prison, the convertor depicted in Fig. 3 was used. This convertor is regulated in Danish Criminal Code, section $\S \S 50-55$, and is reported in detail in Andersen (2018: Table 3). 


\section{Findings}

\section{Research Question A}

Based on prosecutor guidelines from the DPP and sentencing ratings from five prosecutors in the Danish Police, a Danish CHI can be constructed, answering research question A. The Danish CHI includes 339,377 reported crimes in 2016 and the index covers $93 \%$ of all reported crimes according to the criminal code. Moreover, the index was applied to 6 years of crime data from 2011 to 2016, and more than 2,129,550 reported crimes were included. The reported crime data was grouped into its aggregate crime type and multiplied by the equivalent days' imprisonment value (crime weight) derived from the DPP prosecutor guidelines and validated by prosecutor sentencing ratings.

Further, the crime types were grouped in broader categories in order to assess changes of crime patterns in Denmark. The composition of groupings and crime weights are discussed in the methods section of Andersen (2018). The grouping resulted in reducing the 504 offense codes in the Danish Criminal Code to 43 crime categories which easily can be applied to any set of Danish crime data and serve as an analytic tool for all 12 Danish police districts. Figure 2 displays the crime weights for all included categories of offense data.

\section{Research Question B}

How does a Danish CHI, when applied to Danish national police data for 2016, change the relative distribution of proportionate impact of different crime types compared to the raw number of each offense type? Figure 3 displays the total crime volume for selected and grouped offense data from 1 January 2016-31 December 2016. By comparison, Fig. 4 displays the results of applying the Danish $\mathrm{CHI}$ weights to the same crime data.

Theft and related offenses immediately stand out as presenting a much smaller percentage of harm in Fig. 4 (16\%) than indicated by volume in Fig. $3(51 \%)$. Moreover, the harm approach de-emphasizes the relative proportion of vandalism, comprising $1 \%$ of harm versus $7 \%$ of volume. Robbery presents higher harm $(10 \%)$ than indicated by volume (1\%), and also sexual assault increases from $1 \%$ when measured by volume, compared to $10 \%$ measured by harm. In total, crimes against persons stand out when harm is compared to volume, which is illustrated in Figs. 5 and 6.

The application of the Danish CHI to national crime data from 2016 changes the relative distribution of crime types. Looked at by volume, property crime constitutes $81 \%$ of Denmark's total. However, in terms of the harm caused, that percentage is 53\%. When applying the Danish CHI, crimes against persons becomes almost five times the proportion of total harm as it is of total volume. Police Chief Constables already know that these crimes are important, but the statistics make a precise and powerful case to do more for the higher harm crimes or areas, offenders or victims with such crimes. 


\begin{tabular}{|c|c|c|}
\hline GROUPING, ENGLISH TRANSLATION & DFFENCE GRDUP & HARM WEIGHT \\
\hline FRAUD & FRAUL, DECEPTION, ECT. & 60 \\
\hline FRAUD, DATA & FRALID, DECEPTION, ECT. & 60 \\
\hline FRAUD, SOCIAL & FRALD, DECEPTION, ECT. & 90 \\
\hline INDECENT EXPOSURE, VERBAL ANDIOR SHOWING & RAPE AND RELATED DFFENCES & 6 \\
\hline INDECENT EXPOSURE, TOUCH & RAPE AND RELATED DFFENCES & 14 \\
\hline ARSON & ARSON & 180 \\
\hline THEFT FROM SHOP & THEFT AND RELATEQOFFENCES & 6 \\
\hline THEFT, QTHER & THEFT AND RELATEDOFFENCES & 10 \\
\hline THEFT, SAFETY & THEFT AND RELATEDOFFENCES & 180 \\
\hline THEFT, CAR & THEFT AND RELATEDOFFENCES & 14 \\
\hline THEFT, BICYCLE & THEFT AND RELATEDOFFENCES & 6 \\
\hline BREAK IN, HOUSEIAPPARTHENT & BUIRGLARY & 30 \\
\hline BREAK IN, OTHER & BUIRGLARY & 30 \\
\hline CHILD PONOGRAFHY & RAPE AND RELATED DFFENCES & 60 \\
\hline FRAUD, DOKUMENT & FRÁUD, DECEPTION, ECT. & 30 \\
\hline FALSK ALLEGATION & DTHER & 30 \\
\hline IMPRISONED, USE OF MOBILEPHONE UNATHORISED & DTHER & 7 \\
\hline ROBBEFY & ROBEERY & 360 \\
\hline ROBBERY, HOME & ADEBEFY & 1800 \\
\hline DOMESTIC PEACE, VIOLATIOH & ACTSINTENDED TOCAUSE INJUAY ECT & 14 \\
\hline VANDALISM & VANDALISM & 6 \\
\hline VANDALISM,SERIOUS & VANDALISM & 20 \\
\hline HOMICIDE & HDMICIDE AND RELATED OFFENCES & 4320 \\
\hline HOMICIDE, WITHOUT INTENT & HDMICIDE AND RELATED DFFENCES & 180 \\
\hline HOHICIDE, ATTEHT & HOMICIDE AND RELATED OFFENCES & 2160 \\
\hline HOHICIDE, CHILD & HDMICIDE AND RELATED DFFENCES & 5040 \\
\hline HUMAN TRAFFICING & DTHER & 900 \\
\hline SEXUAL ASSUALT, CHILD UNDER 15 YEARS OF AGE & RAPE AND RELATED OFFENCES & 180 \\
\hline THREATS TO KILL & ACTSINTENDED TOCALUSE INJUARY ECT & 30 \\
\hline VIOLEHCE, SIHPLE & ACTSINTENDED TOCAUSE INJUARY ECT & 30 \\
\hline VIOLENCE, SERIOUS & ACTS INTENDED TOCALUSE IN.JURY ECT & 120 \\
\hline VIOLENCE, DEAD & ACTSINTENDED TOCALSE INJUIFY ECT & 2160 \\
\hline VIOLENCE AND THREATS AGAINST GOVERNHENT EMP & ACTSINTENDED TOCAUSE INJUIRY ECT & 30 \\
\hline VIOLENCE AND THREATS AGAINST POLICE OFFICER & ACTS INTENDED TOCALSE INJUIRY ECT & 30 \\
\hline VIOLENCE AGAINST WITNESSES & ACTSINTENDED TOCALUSE INJUIFY ECT & 40 \\
\hline RAPE, CHILD UNDER 12 YEARS OF AGE & RAPE AND RELATED DFFENCES & 1260 \\
\hline RAPE & RAPE AND RELATED DFFENCES & 900 \\
\hline SEXUAL ASSUALT, CHILD UNDER 12 YEARS OF AGE & RAPE ANDRELATED OFFENCES & 180 \\
\hline PRISONER ESCAPE & QTHER & 30 \\
\hline MASK, BAN AGAINST & QTHER & 6 \\
\hline FIREARHS, ILLEGAL POSSESSION & WEAPON & 720 \\
\hline KNIFE, ILLIGAL POSSESSION & WEAPQN & 40 \\
\hline ACCESS WITHOUT PAYHENT & FRAULD, DECEPTION, ECT. & 6 \\
\hline
\end{tabular}

Fig. 2 Crime weights, all included categories in the Danish CHI

\section{Research Question C}

If the Danish CHI is applied to annual national police crime data from to 2011 to 2016 , is the decrease in crime count frequency paralleled by a decrease in Danish CHI value?

By focusing on crime frequency alone, the trend in reported crime volume is for all reported crimes, including those ineligible for the CHI, and is displayed in Fig. 7.

Figure 8 shows that excluding certain crimes to calculate the Danish $\mathrm{CHI}$ based on 93\% of crimes does not challenge the downward trend. Almost the same linear trend can be found when looking only at the reported data included in the Danish CHI. 


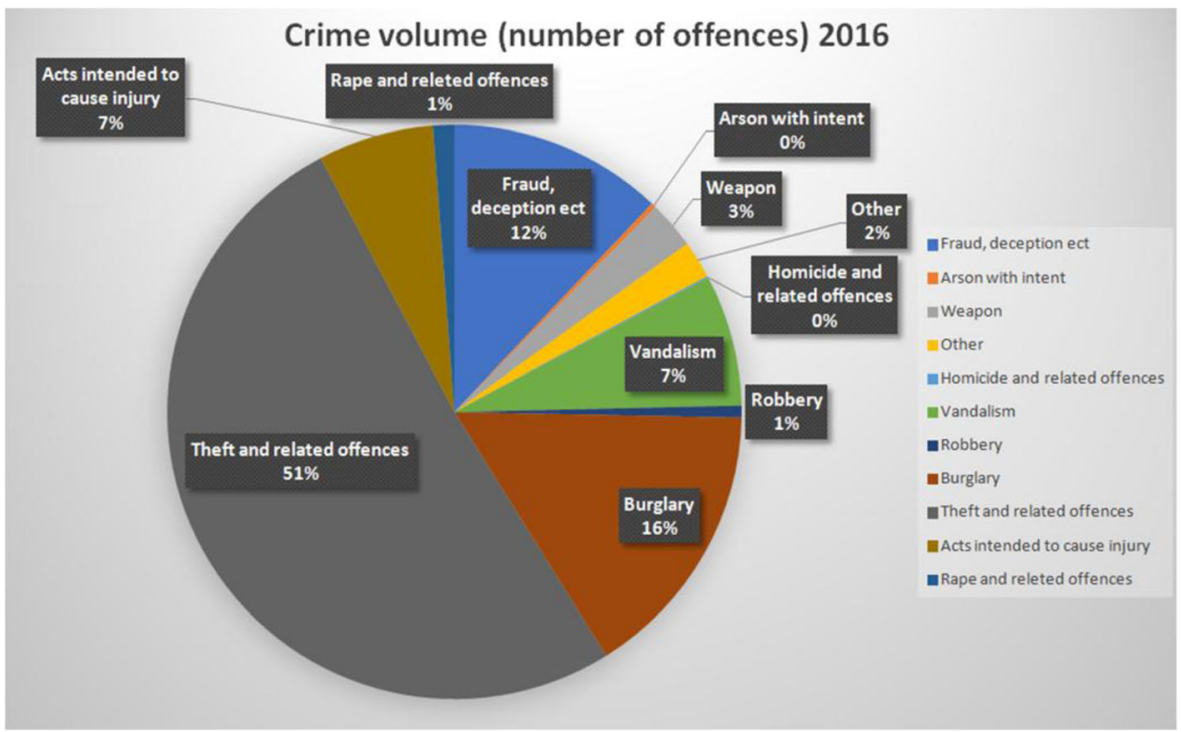

Fig. 3 Crime volume, 2016 (POLSAS)

However, when applying the Danish CHI to the eligible national crime data from 2011 to 2016, the crime trend changes and reveals an increased crime harm as shown in Fig. 9. Note that the metric on the left axis is in the total number of days of imprisonment (or the equivalent in monetary fines) recommended by prosecutorial guidelines for all reported crimes eligible for calculating the Danish CHI.

Unlike the volume trend, the Danish crime harm trend is not linear and not steadily decreasing. While it initially decreased, it reverses in 2015 to rise to a harm level in 2016 that exceeds the harm level for all other years, despite the fact that there were

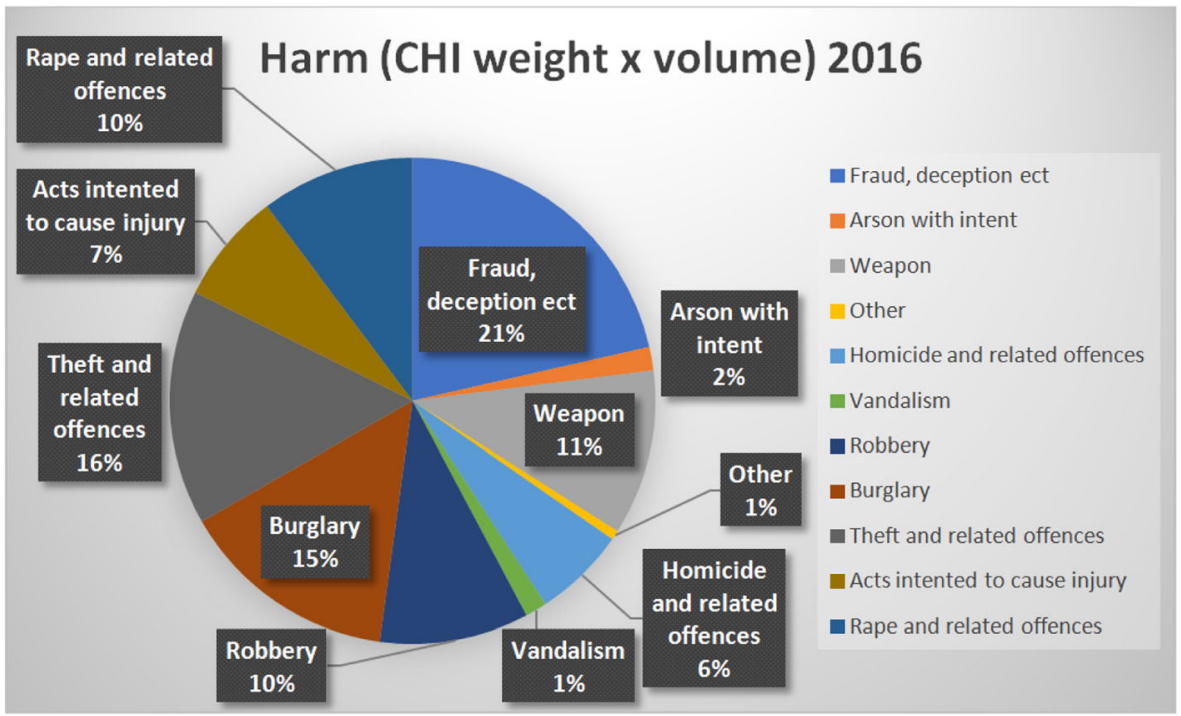

Fig. 4 Crime harm, crime weights applied to crime data 2016 (POLSAS) 


\section{Crime frequency 2016}

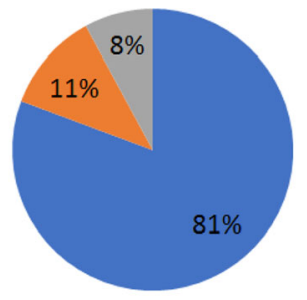

PROPERTY CRIME

CRIMES AGAINST

PERSON

CRIMINAL CODE, OTHER

Fig. 5 Crime frequency, 2016 (POLSAS)

54,000 more reported crimes in 2011 than in 2016. The crime level has gone down from 2011 to 2016, but the data indicates that the crimes that are being committed are more harmful, especially from 2014 to 2016.

Considering the data, no single offense type or category can explain the increased harm level from 2014 to 2016 . However, as outlined in the "A 2015 Change in Rape Recording Practices" section, Danish police changed the standard procedure for how to register reported rapes in mid-2015. As a consequence of this change, the number of rapes reported against persons over 15 years old has increased in 2015 and 2016, but the increase in reported rapes does not necessarily reflect an increase in rapes being committed. To increase the validity of this study, it is therefore important to know if the increased harm level can still be detected when the category rape against person over 15 years old is excluded from the data set. The robust evidence is illustrated in Fig. 10, showing again that the total recommended imprisonment across eligible offenses excluding rape rose from 9,714,057 days in 2011 (after falling to 8,535,745 days in 2014) to 9,760,697 days in 2016.

Splitting the data into the categories (a) crimes against person and (b) property crime also shows a trend of increased harm in both crimes against persons (including rape) and property crime becomes obvious (illustrated in Figs. 11 and 12). In this analysis, however, we see that for crimes against persons, crime volume has risen as well as

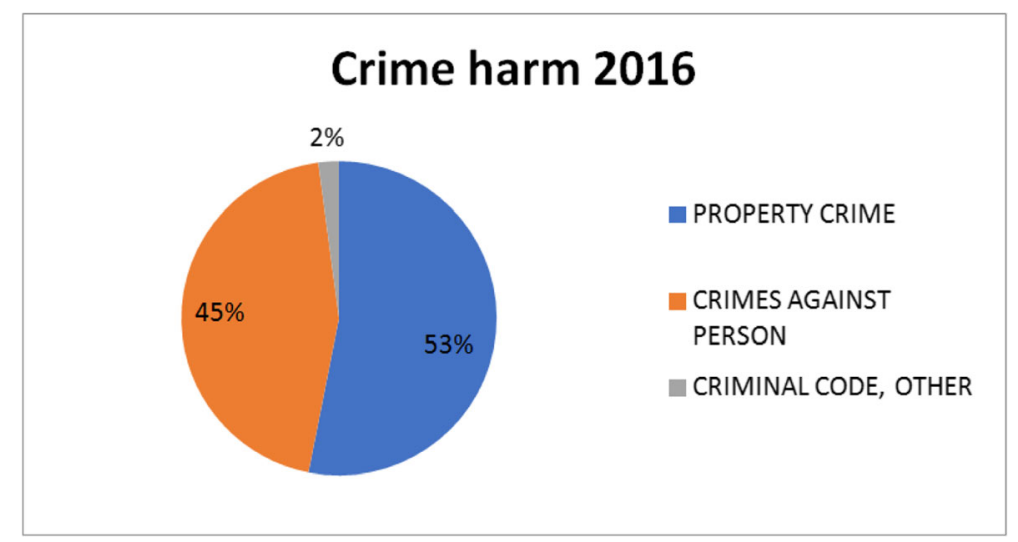

Fig. 6 Crime harm distribution, 2016 (POLSAS) 


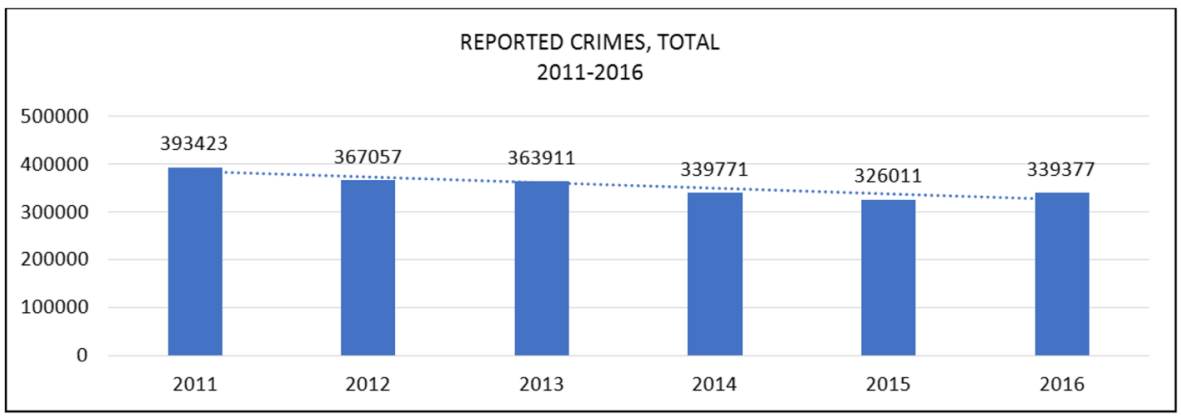

Fig. 7 Reported crimes, total 2011-2016 (POLSAS)

crime harm (Fig. 12). While that fact alone could have signaled increasing harm overall, that fact was clearly swamped by the much greater volume of property crime that dropped substantially in 2011-2016.

Considering the data presented in Fig. 11, the harm associated with property crime has risen from 2011 to 2016, despite the fact that the frequency has decreased during this time period. Looking closely at the data, the decrease in frequency can be explained by a significant drop in reported burglary. ${ }^{2}$ However, in terms of frequency, the category "fraud" has risen from 10,748 in 2011 to 32,802 in 2016. Even though fraud does not have a harm weight more than 60 days of imprisonment, the increase in reported crimes causes large effects on the harm score.

According to the data, "homicide," "sexual offenses," and "rape" are all categories where the reported crime has increased in both frequency and harm from 2011 to 2016. Given the changes in how to record rape occurred in 2015, that category was excluded in a separate analysis. That procedure showed that even after excluding the crime category rape, crimes against persons still generated an increase in relation to harm in the period observed.

The fact that the increased harm score from 2011 to 2016 cannot be explained by a single crime category emphasizes the value of a Danish CHI as a useful tool for Danish Police. These trends would not have been detected if only traditional crime counts were available.

\section{Conclusions}

The results presented in the previous section show some interesting findings and illustrate how the relative distribution of crime types changes when applying a Danish CHI to national police data. The findings illustrate the fact that integrating all crimes in a weighted index represents a useful approach for resource allocation. Because it provides a more nuanced measure of crime, the Danish CHI helps illustrate that the crime (volume) drop was accompanied by a rise in harm level. This analysis certainly has limitations and can no doubt be improved in future work. Yet the capacity of a CHI to reveal a very different result from counting crime

\footnotetext{
${ }^{2}$ As illustrated in Fig. 2 (p. 48), burglary is assigned a harm weight of a recommended 30 days of imprisonment under prosecutorial guidelines.
} 


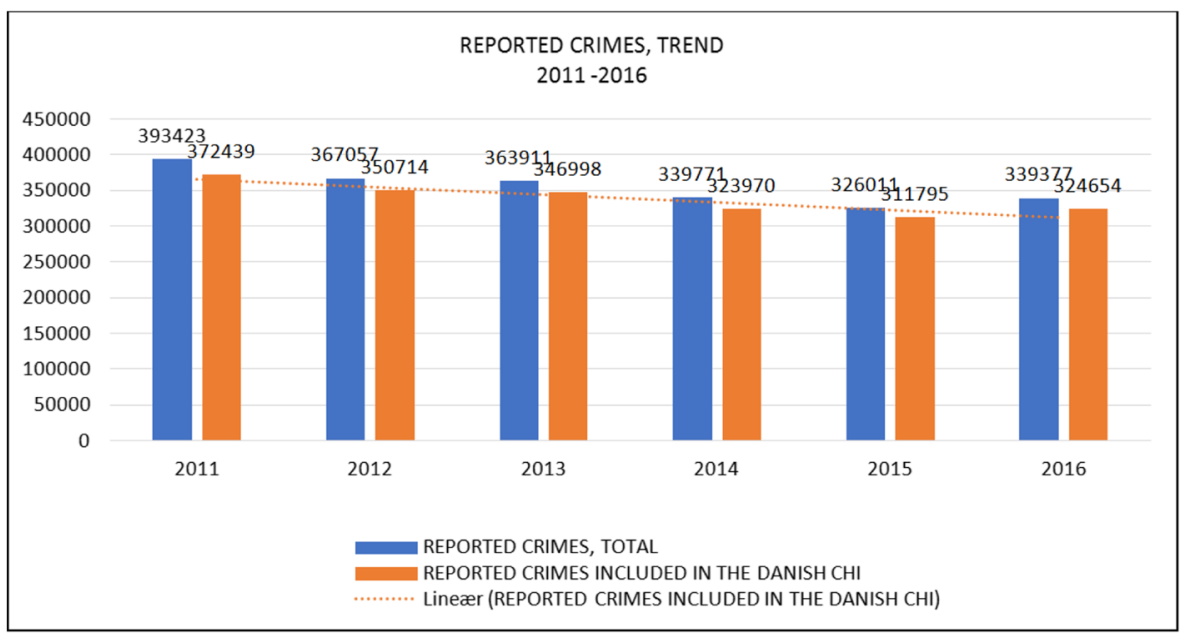

Fig. 8 Total reported crimes versus included crimes, 2011-2016 (POLSAS)

volume is an important piece of evidence for deciding whether to supplement annual reports on volume with analyses of CHI scores.

\section{Limitations}

According to Sherman et al. (2016), crime harm weights should be assigned to particular crimes rather than basing the harm weights on broad categories, as is done in this research. Despite the recommendation from Sherman et al. (2016), it has not been possible to create harm weights at a highly granular offense codes level. This was due to the data quality of the police data and the fact that any manual sorting of the data would have been too time consuming to carry out within the scope of this thesis. However, all groupings of the offense codes were reviewed by two prosecutors, who

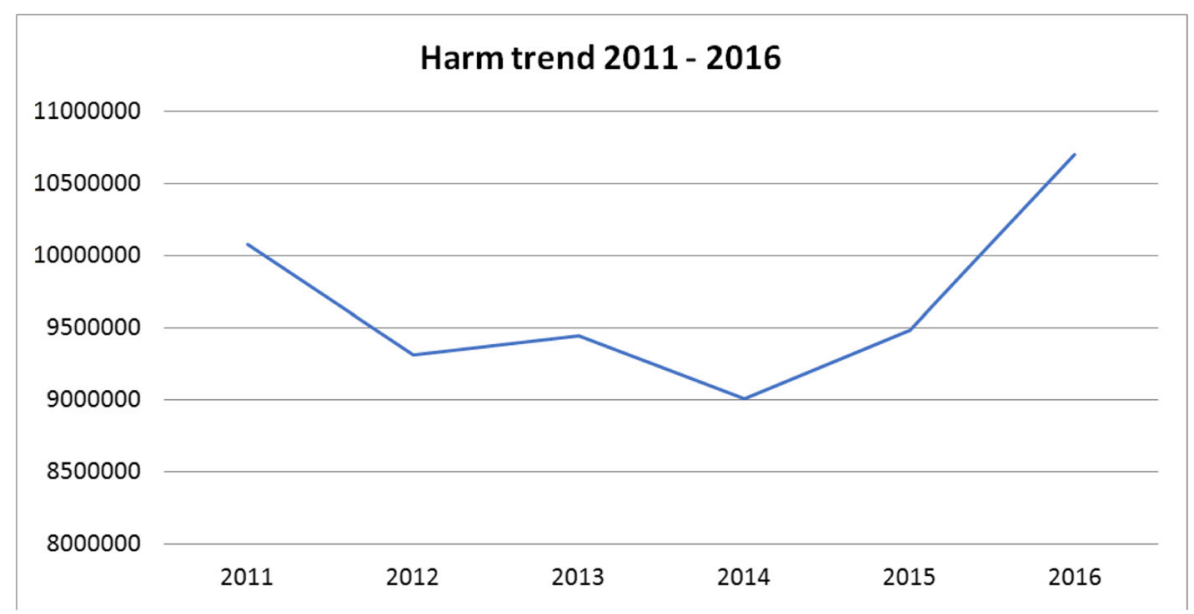

Fig. 9 Harm trend, 2011-2016 (POLSAS). Annual totals: $2011=10,021,857 ; 2012=9,264,796 ; 2013=$ $9,387,293 ; 2014=8,951,545 ; 2015=9,431,442 ; 2016=10,631,897$ 


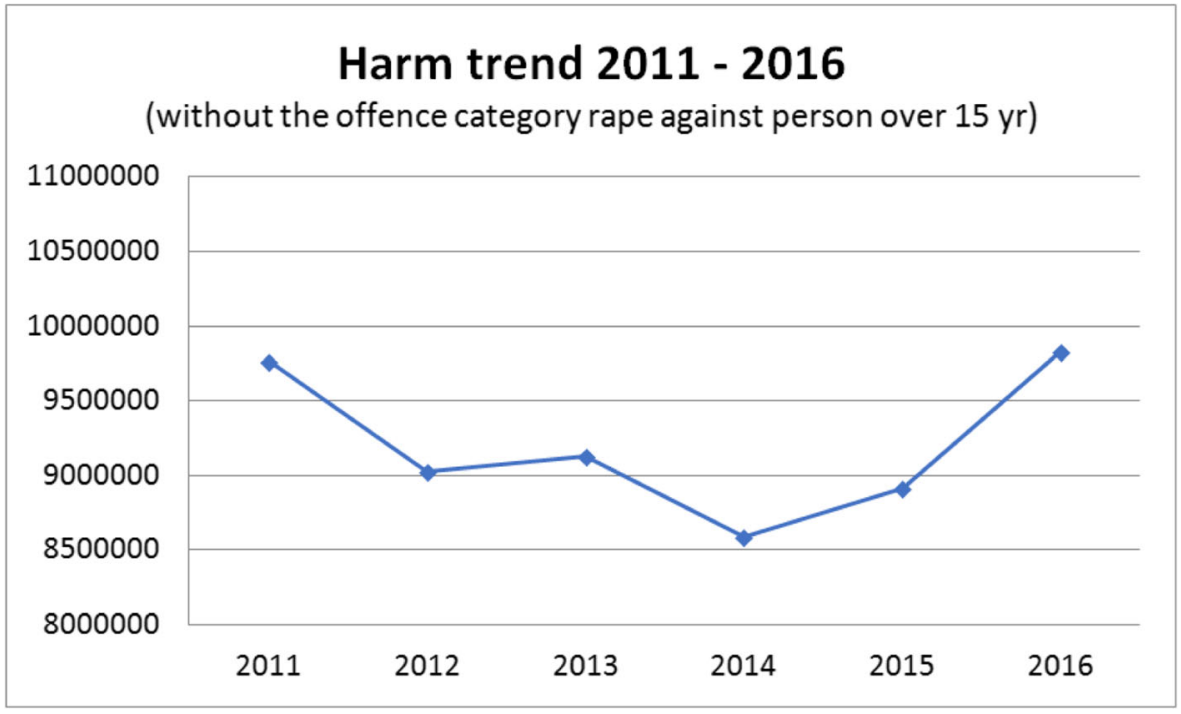

Fig. 10 Harm trend 2011-2016 (POLSAS), offense category "raped" excluded. Annual totals: $2011=$ $9,714,057 ; 2012=8,979,496 ; 2013=9,071,393 ; 2014=8,535,745 ; 2015=8,866,242 ; 2016=9,760,697$

were not part of the subsequent crime sentence coding, in order to make sure that the harm weights reflected all included crimes according to the Criminal Code.

Further validation studies are required to increase the reliability of the Danish CHI. It could clearly benefit from future studies trying to split up some of the broader crime categories in order to discover whether that would lead to different results. Despite the fact that the broad grouping of offense categories poses some threat to the validity of

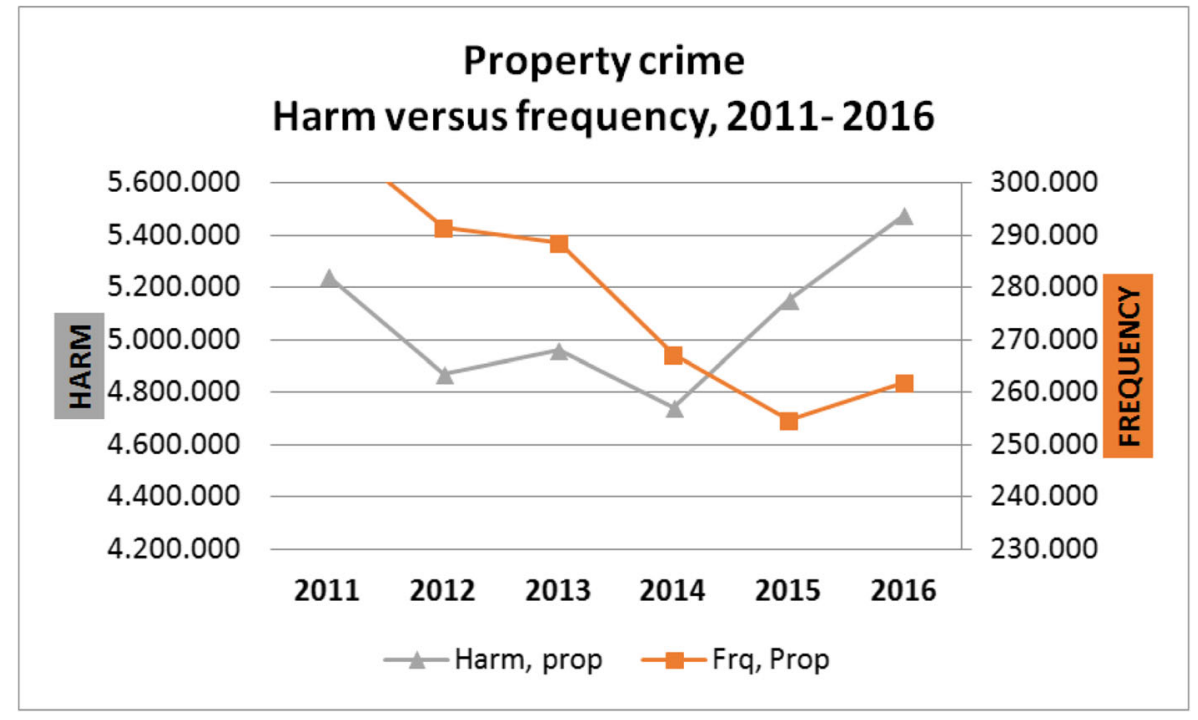

Fig. 11 Harm-trend vs. frequency trend, property crime (POLSAS) 


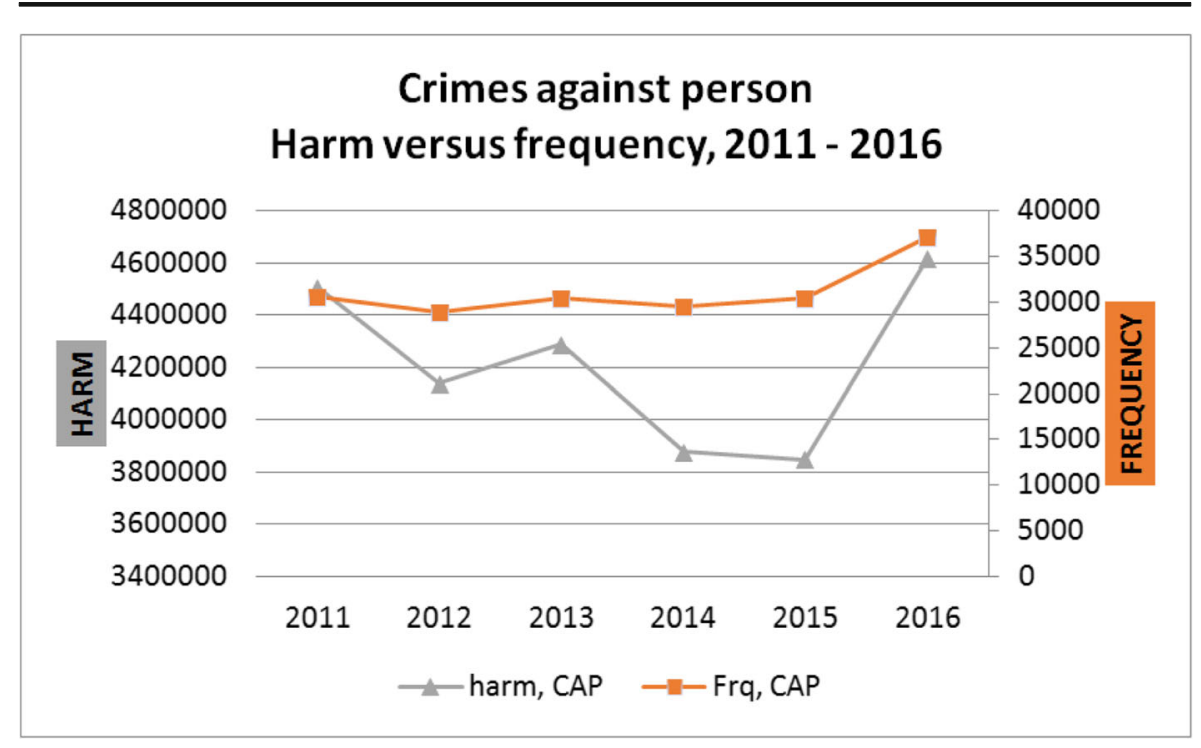

Fig. 12 Harm-trend vs. frequency trend, crimes against person (POLSAS)

the Danish CHI, the index in its current form is still a valid instrument for the Danish Police to refine the measurement of crime.

Poor data coding quality of digital records poses a threat to Danish Police adopting and applying a (reliable) Danish CHI. Therefore, it could be argued that Danish Police should rearrange its offense groupings to be more aligned with analytical tasks for which the data could be used. However, this is a very expensive solution and it would demand a restructure of the entire IT platform.

\section{To Include or Exclude Police-Generated Offenses in the Danish CHI}

The Cambridge CHI distinguishes between crimes reported to the police and those "proactively generated" through enforcement. The argument for excluding policeinitiated offenses is the fact that police enforcement actually contributes to a statistical crime increase if unreported crime detected by police surveillance would still have to count as "one crime"; the higher the arrest rates, the higher the crime rate. Moreover, Sherman et al. (2016) argue that police-initiated reports (with $100 \%$ clearance by arrests) do not reliably measure harm experienced by the population. Rather, Sherman et al. argue that police-initiated reports measure the resources invested by the police. Sherman et al. (2016) state that "(...) the principle (is) that policing is an independent variable, which cannot be, simultaneously, a dependent variable" (Sherman et al. 2016, p. 2). Therefore, Sherman et al. argue that any CHI will have to exclude drug arrests, traffic arrests, shoplifting detected by store security officers, and similar detections.

However, it can be argued that while excluding police-initiated offenses when measuring and illustrating the overall harm to victims and society increases the reliability, leaving out these offenses becomes more problematic when it comes to applying the harm index for targeting reasons. If the police should target the "power 
few" offenders that account for the dominating part of the harm to victim and/or society, leaving out narcotics (possession and drug sales) decreases the accuracy of the harm index. However, including narcotics in a Danish CHI when applied to ordinary police data will, for reasons stated by Sherman et al. (2016), affect the reliability. Though, while agreeing with Sherman et al. (2016) that including such proactive detected offenses can present a misleading picture to the actual rate at which some offenses occur, this is equally a consideration when looking at traditional crime counts.

Therefore, it is proposed to create an appendix to the Danish CHI that includes all available offense codes. Such an appendix would be created along the same methodology lines as the original Danish CHI. An appendix containing police-initiated offenses could be put to use, for example, for targeting activities (depending on the needs of the analysis) to raise the overall accuracy without decreasing the reliability. The appendix could also be applied to targeting decisions of proactive policing itself, tying the investment in specific targets (from gangs to areas) to the $\mathrm{CHI}$ value of the offenses that are associated with arrests or convictions.

\section{Next Steps for a Danish CHI}

Despite its limitations, the Danish CHI still serves as an important contribution towards Danish Police becoming more evidence-based. This simple, easily operationalized way of measuring harm caused to victims and society has the potential to improve the identification of crime trends and resource allocation in policing. Currently, in the Danish Police, there exists no meaningful "bottom line" indicator of whether public safety is actually improving or declining in any given year or place. The Danish CHI has the potential to fill this gap and serve as a more meaningful bottom line indicator which can be used in many testing, tracking, and targeting initiatives. Moreover, having an addition to the traditional crime count ensures that police, policy makers, and the public are better informed on rates and trends of crime, the risks posed, and resources required.

For these reasons, the North Zealand District of the Danish Police has agreed to serve as a test area for developing the Danish CHI. A full description of the plan is presented in Andersen (2018). Subsequent reports on the development and impact of the Danish CHI are planned to help guide evidence-based policing in putting better tools into practice for targeting, testing, and tracking police resources.

Acknowledgements This research was supported by a grant from Trygfonden, the Safety Foundation of Denmark, to the Danish Police, supporting scholarships for Danish police professionals to take the Cambridge Police Executive Programme's course for the Master of Studies degree in Applied Criminology and Police Management, Institute of Criminology, University of Cambridge. The first author expresses thanks to her colleagues within the Danish Police and to all of the prosecutors who helped her translate prosecutorial guidelines and criminal law into crime harm weights.

Open Access This article is distributed under the terms of the Creative Commons Attribution 4.0 International License (http://creativecommons.org/licenses/by/4.0/), which permits unrestricted use, distribution, and reproduction in any medium, provided you give appropriate credit to the original author(s) and the source, provide a link to the Creative Commons license, and indicate if changes were made. 


\section{References}

Andersen, H. (2018). How measurement matters: the creation of a Danish Crime Harm Index and its initial application to national police data. M.St. Thesis in Applied Criminology and Police Management, University of Cambridge.

Anklagemyndigheden. (2017). Rigsadvokatmeddelsen. Copenhagen: Justisministeriet.

Babyak, C., Wallace, M., Turner, J., \& Matarazzo, A. (2009). Measuring crime in Canada: introducing the Crime Severity Index and improvements to the Uniform Crime Reporting Survey. Ottawa: Statistics Canada.

Bryman, A. (2004). Social research methods (2nd ed.). New York: Oxford University Press.

Cronbach, L. J. (1951). Coefficient alpha and the internal structure of the tests. Psychometrika, 16, 267-334.

Curtis-Ham, S. and Walton, D. (2017). The New Zealand Crime Harm Index: quantifying harm using sentencing data. Policing. Oxford University Press, pp. 1-13

Mitchell, R. (2017). The usefulness of a crime harm index: analyzing the Sacramento Hot Spot Experiment using the California Crime Harm Index (CA-CHI). Journal of Experimental Criminology, pp. 1-11 Published Online 16 December.

Neyroud, P. W. (2016). The ethics of learning by testing: the police, professionalism and researching the police. In M. Cowburn, L. Gelsthorpe, \& A. Wahidin (Eds.), Research ethics in criminology-dilemmas, issues and solutions. London: Routledge.

Ratcliffe, J. (2014). Towards an index for harm-focused policing. Policing, 9(2), 164-183.

Rigspolitiet (2010). POLSPOT. Nationalt Efterforskningscenter, Ejby.

Rinaldo, M. (2016). Comparing crime hotspots and crime harm-spots in a Swedish City: a descriptive analysis. Master thesis. University of Cambridge, UK.

Sherman, L. W. (2007). The power few: experimental criminology and the reduction of harm. Journal of Experimental Criminology, 3(4), 299-321.

Sherman, L. (2011). 'Al Capone, the Sword of Damocles, and the Police-Corrections Budget Ratio.' Criminology and Public Policy 10: 195-206.

Sherman, L. W. (2013). The rise of evidence-based policing: targeting, testing, and tracking. Crime and Justice, 42(1), 377-451.

Sherman, L. W., Neyroud, P., \& Neyroud, E. (2016). The Cambridge Crime Harm Index: measuring total harm from crime based on sentencing guidelines. Policing, 10(3), 171-183.

Helle Andersen, MSt (Cantab), is an analyst in the National Centre of Investigation (NCI) of the Danish Police.

Katrin Mueller-Johnson, Ph.D. (Cornell), is a Senior Lecturer in Applied Criminology at the University of Cambridge, Institute of Criminology. 